\title{
Which treatment protocol, among classical methods and/or various laser applications is the most effective in root canal disinfection, in vitro? A systematic review
}

\author{
Joanna Theodosopoulou ${ }^{1}$, Alexandra Tsigarida ${ }^{2}$, Konstantinos Chochlidakis ${ }^{3}$ \\ ${ }^{1}$ Harvard School of Dental Medicine (HSDM), The Forsyth Institute, Private Practice, Athens, Greece;
${ }^{2}$ Department of Periodontology, The Ohio State University, Columbus, USA;
${ }^{3}$ Department of Prosthodontics, Eastman Institute for Oral Health, Rochester, USA.
Email: joanna_theodosopoulou@yahoo.gr
}

Received 20 July 2011; revised 11 October 2011; accepted 26 October 2011.

\section{ABSTRACT}

Purpose: The aim of this systematic review was to answer the question "Which treatment protocol, among classical methods and/or various laser applications is the most effective in root canal disinfection, in vitro". Materials and Methods: A MEDLINE, a Cochrane and an Embase search (three specified searches) were conducted to identify randomized controlled trials (RCT) until June 2010, conducted on human teeth and published in English, German or French language, examining the root canal disinfection after the use of lasers with or without mechanical instrumentation. Additionally, hand search was conducted and contact with authors, when needed. Results: The MEDLINE, the Cochrane and the EMBASE search identified 240, 28, and 35 published articles, respectively. Ten articles from the MEDLINE and 5 articles from the Cochrane search (that were also identified in the MEDLINE search) met the inclusion and validity assessment criteria. In $\boldsymbol{E}$. faecalis elimination, instrumentation of the root canal and diode laser/665 nanometer/1 Watt (diode laser/665 nm/1 W) irradiation with the combined effect of Methylene Blue (MB) as photosensitizing agent $(\log C F U / m l=1.636)$ seemed to be the best method. In $P$. aeruginosa and in $A$. naeslundii elimination, instrumentation of the root canal followed by irrigation with $5.5 \% \mathrm{NaOCl}$ (log$\mathrm{CFU} / \mathrm{ml}=0$ ) seemed to be the best method. In general, instrumentation of the root canal followed by irrigation with $5.25 \% \mathrm{NaOCl}(\log \mathrm{CFU} / \mathrm{ml}=0)$ and instrumentation of the root canal and Er: YAG laser/ $2940 \mathrm{~nm} / 0.8 \mathrm{~W}$ irradiation $(\log C F U / \mathrm{ml}=1.924)$ seemed to be the best (polymicrobial studies). Conclusions: There are treatment protocols with the assistance or not of laser irradiation that can eliminate $E$. faecalis, $E$. coli and $S$. aureus inside the root canal. However, there is a serious number of $S$. anginosus, $F$. nuclea- tum, A. naeslundii and $P$. aeruginosa that remain inside the root canal even after laser irradiation. New research is needed in order to set a treatment protocol effective in the root canal disinfection from all bacteria that are related to endodontic origin pathology.

Keywords: Lasers; Classical Methods; Endodontic; Root Canal Therapy; Dentin; Bacteria; Disinfection

\section{INTRODUCTION}

One of the most crucial and fundamental stages of endodontic therapy is the root canal disinfection in its threedimensional network of dentinal tubules. Nevertheless, persistence of infection in the root canal is responsible for long-term failures and need for endodontic therapy retreatments.

It is generally accepted that microorganisms tend to remain in the root canal even after proper preparation and are responsible for flare-ups, after the completion of the endodontic therapy. The most common of these microorganisms are: Fusobacterium nucleatum, Enterococcus faecalis, Prevotella intermedia, Streptococcus anginosa, Treponima denticolla, Porphyromonas gingivalis [1-4].

During the last years, laser irradiation has been additionally introduced in root canal preparation, trying to gain acceptance for its disinfection ability in comparison with the common mechanical instrumentation and irrigation procedures.

Many studies examine the effectiveness of Nd:YAG, diode, Er,Cr:YSGG and Er:YAG laser, when used in different wavelengths, solely, or in addition with various solutions in the bacterial elimination inside the root canals.

The purpose of this systematic review was to answer the question "Which treatment protocol, among classical methods and/or various laser applications is the most effective in root canal disinfection, in vitro". 


\section{MATERIALS AND METHODS}

\subsection{Literature Search}

One electronic search of MEDLINE from 1966 to June 2010 (Table 1), one Cochrane (Table 2) and one Embase search from 1945 to June 2010 (Table 3) were conducted.

Table 1. Medline search strategy.

\begin{tabular}{|c|c|c|}
\hline \# & Search history & Results \\
\hline \#13 & $\begin{array}{l}\text { Search \#12 Limits: Humans, English, French, } \\
\text { German, Greek, Modern }\end{array}$ & 240 \\
\hline \#12 & Search \#11 AND \#1 & 282 \\
\hline$\# 12$ & Search \#11 AND \#1 & 13,136 \\
\hline \#11 & Search \#7 AND \#10 & 15,641 \\
\hline$\# 10$ & Search \#8 OR \#9 & 14,900 \\
\hline$\# 9$ & Search (root canal therapy) & 1622 \\
\hline$\# 8$ & Search (endodontically treated teeth) & $4,830,685$ \\
\hline$\# 7$ & Search \#1 OR \#2 OR \#3 OR \#4 OR \#5 OR \#6 & 138,039 \\
\hline \#6 & Search (tooth OR teeth) & $1,267,279$ \\
\hline$\# 5$ & Search bacteria & $3,639,649$ \\
\hline$\# 4$ & Search method & 19,546 \\
\hline$\# 3$ & Search dentin & 14,477 \\
\hline$\# 2$ & Search endodont* & 137,179 \\
\hline$\# 1$ & Search laser & 240 \\
\hline
\end{tabular}

Table 2. Cochrane search strategy.

\begin{tabular}{ccc}
\hline$\#$ & Search history & Results \\
\hline$\# 1$ & Laser & 6294 \\
$\# 2$ & Endodont* & 1174 \\
$\# 3$ & Dentin & 1427 \\
$\# 4$ & Method & 241,235 \\
$\# 5$ & Bacteria & 4978 \\
$\# 6$ & (Tooth OR teeth) & 7062 \\
$\# 7$ & (\#1 OR \#2 OR \#3 OR \#4 OR \#5 OR \#6) & 248,592 \\
$\# 8$ & (Endodontically treated teeth) & 89 \\
$\# 9$ & (Root canal therapy) & 401 \\
$\# 10$ & (\#8 OR \#9) & 442 \\
$\# 11$ & $(\# 7$ AND \#10) & 422 \\
$\# 12$ & $(\# 1$ AND \#11) & 28 \\
\hline
\end{tabular}

Table 3. Embase search strategy.

\begin{tabular}{ccc}
\hline$\#$ & Search history & Results \\
\hline 1 & Laser & 106,390 \\
2 & Endodont* & 1076 \\
3 & Dentin & 2983 \\
4 & Method & 785,208 \\
5 & Bacteria & 121,213 \\
6 & (Tooth OR teeth) & 40,114 \\
7 & (\#1 OR \#2 OR \#3 OR \#4 OR \#5 OR \#6) & $5,138,833$ \\
8 & (Endodontically treated teeth) & 43 \\
9 & (Root canal therapy) & 64 \\
10 & (\#8 OR \#9) & $1,426,192$ \\
11 & (\#7 AND \#10) & 218,687 \\
12 & (\#1 AND \#11) & 225,630 \\
13 & Limit 12 to humans, English or French or German & 35 \\
\hline
\end{tabular}

\subsection{Inclusion Criteria-Validity}

Three independent reviewers examined all the identified abstracts to determine whether they met the following criteria:

1) Study in vitro.

2) Conducted in human teeth.

3) Related to the question.

4) Experimental and control group.

5) Quantitative results provided.

6) English, German, French languages.

Whenever it was not possible to make this determination, the article was examined in full text. Subsequently, all relevant articles were obtained and a determination whether or not they met the inclusion criteria was made by three reviewers. It is important to state that only studies measuring the bactericidal effect of lasers and other procedures were included. The studies that examined the removal of smear layer or debris, the morphological or histological changes, the apical leakage after obturation and the dentin permeability were excluded, as irrelevant to our question (Tables 8-12).

All articles that met the inclusion criteria were assessed for validity. Validity was determined on a 7-point scale (Table 4) and studies not meeting 5 or more of the 7 validity criteria were excluded.

All articles were classified by evidence level (Table 5) (EBM://cebm.jr2.ox.uk/docs/levels.html) and then assessed for Validity (http://www.cebm.utoronto.ca/teach/materials/therapy.htm) (Table 6). 
Table 4. Validity assessment criteria ${ }^{1}$.

1. Was the assignment of patients of treatment randomised?

2. Was the randomisation list concealed?

3. Was the follow-up of patients sufficiently long and complete?

4. Were all patients analysed in the groups to which they were randomised?

5. Were patients and clinicians blinded to the treatment being received?

6. Aside from the experimental treatment, were the groups treated equally?

7. Were the groups similar at the start of the trial?

Table 5. Clinical evidence levels ${ }^{2}$.

\begin{tabular}{ccc}
\hline Level of evidence & Study Type & $\#$ \\
\hline 1A & Randomized control trial (RCT) & 6 \\
1B & Systematic Review of RCTs & \\
2 & Controlled Trial Systematic review of CCTs & 2 \\
3 & Cohort Study(CCS) Systematic review of CSs & 2 \\
4 & Case Control Study Systematic Review of CCSs & 0 \\
5 & Case Series & 0 \\
NA & Expert's Opinion Narrative Review & 0 \\
Non validated & Cross Sectional Case Reports & 0 \\
\hline
\end{tabular}

Table 6. Validity assessment criteria application.

\begin{tabular}{|c|c|c|c|c|c|c|c|}
\hline Reference & 1 & 2 & 3 & 4 & 5 & 6 & 7 \\
\hline De Souza, E. B. et al., 2008 & $\mathrm{Y}$ & $\mathrm{Y}$ & $\mathrm{Y}$ & $\mathrm{Y}$ & $\mathrm{N}$ & $\mathrm{Y}$ & $\mathrm{Y}$ \\
\hline Fimple, J. L. et al., 2008 & $\mathrm{Y}$ & Y & Y & Y & $\mathrm{N}$ & Y & $\mathrm{Y}$ \\
\hline Fonseca, M. B. et al., 2008 & $\mathrm{~N}$ & $\mathrm{~N}$ & $\mathrm{Y}$ & Y & $\mathrm{N}$ & $\mathrm{Y}$ & $\mathrm{Y}$ \\
\hline Bergmans, L. et al., $2008^{4}$ & $\mathrm{Y}$ & $\mathrm{Y}$ & $\mathrm{Y}$ & $\mathrm{Y}$ & $\mathrm{N}$ & $\mathrm{Y}$ & $\mathrm{Y}$ \\
\hline Foschi, F. et al., 2007 & $\mathrm{Y}$ & Y & Y & Y & $\mathrm{N}$ & Y & $\mathrm{Y}$ \\
\hline Wang, Q. Q. et al., $2007^{4}$ & $\mathrm{Y}$ & $\mathrm{Y}$ & $\mathrm{Y}$ & $\mathrm{Y}$ & $\mathrm{N}$ & $\mathrm{Y}$ & $\mathrm{Y}$ \\
\hline Gordon, W. et al., 2007 & $\mathrm{~N}$ & $\mathrm{~N}$ & Y & Y & $\mathrm{N}$ & $\mathrm{Y}$ & $\mathrm{Y}$ \\
\hline Schoop, U. et al., 2007 & $\mathrm{~N}$ & $\mathrm{~N}$ & $\mathrm{Y}$ & $\mathrm{Y}$ & $\mathrm{N}$ & $\mathrm{Y}$ & $\mathrm{Y}$ \\
\hline Soukos, N. S. et al., 2006 & $\mathrm{~N}$ & $\mathrm{~N}$ & $\mathrm{Y}$ & $\mathrm{Y}$ & $\mathrm{N}$ & $\mathrm{Y}$ & $\mathrm{Y}$ \\
\hline Vezzani, M. S. et al., 2006 & $\mathrm{~N}$ & $\mathrm{~N}$ & Y & Y & $\mathrm{N}$ & Y & $\mathrm{Y}$ \\
\hline Bergmans, L. et al., $2006^{4}$ & $\mathrm{Y}$ & $\mathrm{Y}$ & Y & Y & $\mathrm{N}$ & $\mathrm{Y}$ & Y \\
\hline Perin, F. M. et al., 2004 & $\mathrm{~N}$ & $\mathrm{~N}$ & Y & Y & $\mathrm{N}$ & $\mathrm{Y}$ & $\mathrm{Y}$ \\
\hline Kreisler, M. et al., 2003 & $\mathrm{~N}$ & $\mathrm{~N}$ & Y & Y & $\mathrm{N}$ & $\mathrm{Y}$ & $\mathrm{Y}$ \\
\hline Dostalov $\alpha$, T. et al., 2002 & $\mathrm{~N}$ & $\mathrm{~N}$ & Y & Y & $\mathrm{N}$ & Y & $\mathrm{Y}$ \\
\hline Schoop, U. et al., 2002 & $\mathrm{~N}$ & $\mathrm{~N}$ & $\mathrm{Y}$ & $\mathrm{Y}$ & $\mathrm{N}$ & $\mathrm{Y}$ & $\mathrm{Y}$ \\
\hline Piccolomini, R. et al., $2002^{4}$ & $\mathrm{Y}$ & $\mathrm{Y}$ & $\mathrm{Y}$ & $\mathrm{Y}$ & $\mathrm{N}$ & $\mathrm{Y}$ & $\mathrm{Y}$ \\
\hline Folwaczny, M. et al., $2002^{4}$ & $\mathrm{Y}$ & Y & $\mathrm{Y}$ & $\mathrm{Y}$ & $\mathrm{N}$ & $\mathrm{Y}$ & Y \\
\hline Moritz, A. et al., 1999 & $\mathrm{Y}$ & $\mathrm{Y}$ & Y & Y & $\mathrm{N}$ & $\mathrm{Y}$ & $\mathrm{Y}$ \\
\hline Mehl, A. et al., 1999 & $\mathrm{Y}$ & $\mathrm{Y}$ & Y & Y & $\mathrm{N}$ & $\mathrm{Y}$ & $\mathrm{Y}$ \\
\hline Moritz, A. et al., 1997 & $\mathrm{~N}$ & $\mathrm{~N}$ & Y & Y & $\mathrm{N}$ & $\mathrm{Y}$ & $\mathrm{Y}$ \\
\hline Ramskold, L. O. et al., 1997 & $\mathrm{~N}$ & $\mathrm{~N}$ & Y & Y & $\mathrm{N}$ & Y & $\mathrm{Y}$ \\
\hline Gutknecht, N. et al., 1997 & $\mathrm{~N}$ & $\mathrm{~N}$ & Y & Y & $\mathrm{N}$ & Y & Y \\
\hline Moshonov, J. et al., 1995 & $\mathrm{~N}$ & $\mathrm{~N}$ & Y & Y & $\mathrm{N}$ & Y & Y \\
\hline Fegan, S. E. et al., 1995 & $\mathrm{~N}$ & $\mathrm{~N}$ & $\mathrm{Y}$ & Y & $\mathrm{N}$ & Y & $\mathrm{Y}$ \\
\hline Hardee, M. W. et al., 1994 & $\mathrm{~N}$ & $\mathrm{~N}$ & Y & $\mathrm{Y}$ & $\mathrm{N}$ & Y & $\mathrm{Y}$ \\
\hline
\end{tabular}

${ }^{1}$ Evidence-Based Medicine. How to Practise and Teach EBM, 2nd edition, Sackett, D. et al., Churchill Livingstone, Edinburgh, UK.

${ }^{2} \mathrm{http}: / / \mathrm{www} . c e b m \cdot n e t /$ index.aspx?o=1025

${ }^{3}$ Not applicable.

${ }^{4}$ Also identified in Cochrane search.

\subsection{Data Analysis}

All results were converted and finally expressed in log$\mathrm{CFU} / \mathrm{ml}$ (logarithm of the Colony Forming Units per milliliter) of the bacteria that were found after root canal preparation and laser or not laser irradiation. This was done for all specimens of all the studies.

Data from the studies that met validity criteria were extracted and classified by the method used for each bacterial group (Tables 15-21), for the polymicrobial studies (Table 22) and for all of the studies together (Table 23).

\section{RESULTS}

\subsection{Medline Search}

The MEDLINE search from 1966 to June 2010 identified 240 articles (Table 7). From 240 articles identified by the search, the hand examination of titles, abstracts and articles in full text revealed that 120 were irrelevant and 120 appeared to be relevant. Of the 120 relevant articles, 6 were in vivo studies, 5 expert's opinion, 6 narrative reviews, 3 case reports, 1 was an animal study and the remaining 99 were relevant in vitro studies.

Of the 99 relevant in vitro studies:

- Seventy were excluded because they were not related to the question.

Analytically:

Seventeen examined the removal of smear layer and debris (Table 8).

Twenty four examined morphological changes of the root canal (Table 9).

Twelve examined obturation and apical leakage after obturation (Table 10). Eleven examined dentin permeability (Table 11).

Five examined the thermal effects on the dentin (Table 12).

One examined adhesion of root canal sealers [5].

- One was excluded because it was not conducted on human teeth but on human teeth slices [6].

- Three were excluded because they did not provide quantitative results [7-9].

From the remaining 25 articles, 15 [10-24] were excluded because they met less than 5 of 7 validity criteria (Table 13). Ten articles [25-34] were finally included. Details of the included 10 studies are presented in Table 14.

\subsection{Cochrane Search}

The Cochrane search identified 28 articles. From these 28 articles the hand examination of titles, abstracts and articles in full text, revealed that 16 were irrelevant to the question and 12 appeared to be relevant. Of the 12 articles, 7 did not meet the inclusion criteria and the remaining 5 were relevant in vitro studies. All of the 5 relevant in vitro studies were also identified by the Medline 
Table 7. Search results.

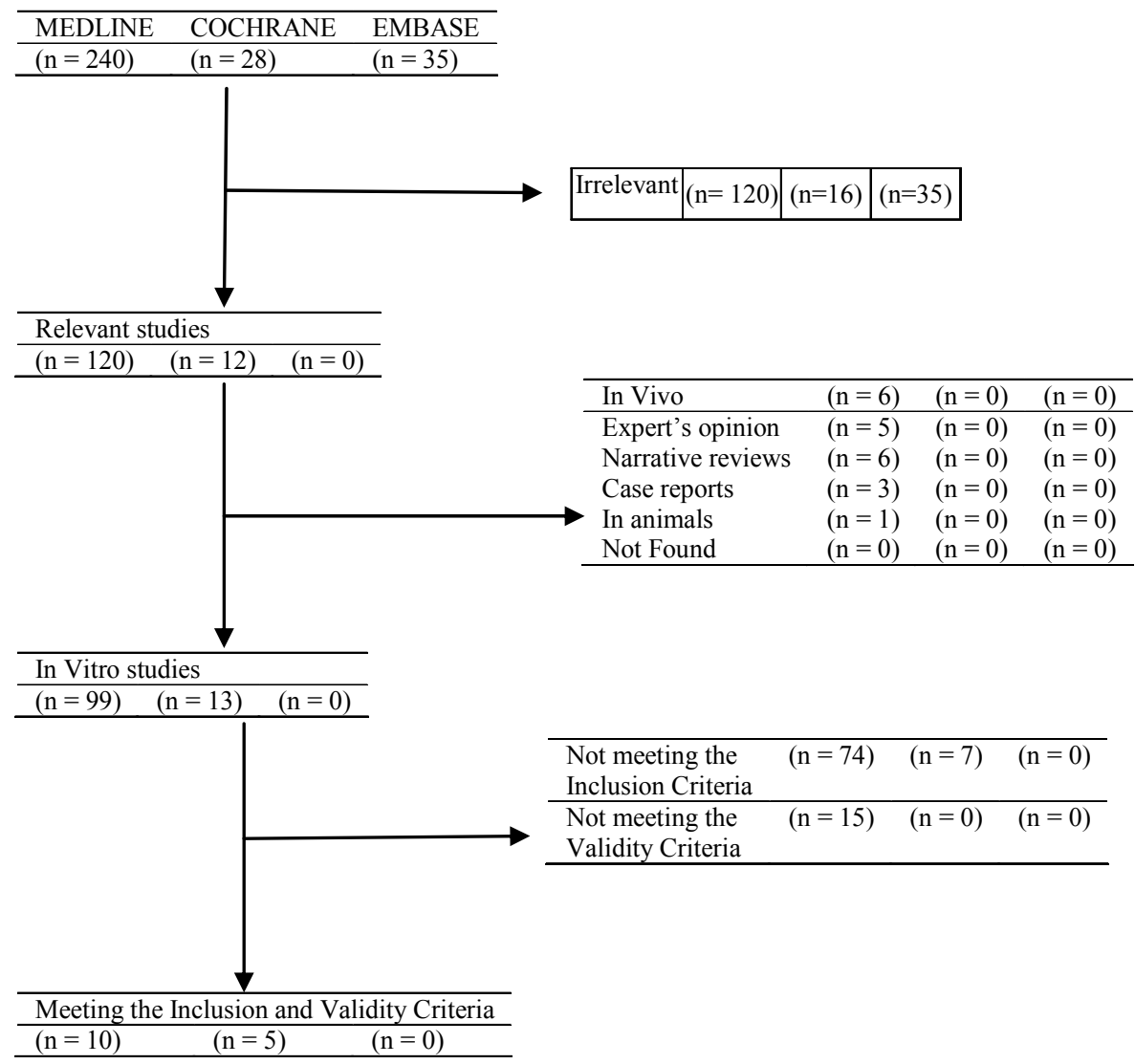

Table 8. Excluded studies: remove smear layer/debris.

\begin{tabular}{cc}
\hline Reference & Detail \\
\hline Soares F. et al., 2008 & Remove smear layer \\
\hline Moshonov J. et al., 2004 & Remove smear layer \\
\hline Moshonov J. et al., 2003 & Remove smear layer \\
\hline Matsuoka E. et al., 1998 & Remove smear layer \\
\hline Takeda F. H. et al., 1998 & Remove smear layer \\
\hline Arrastia-Jitosho A. M. et al., 1998 & Remove smear layer \\
\hline Takeda F. H. et al., 1998 & Remove smear layer \\
\hline Radatti D. A. et al., 2006 & Remove debris \\
\hline Blum J. Y. et al., 1997 & Remove debris \\
\hline Harashima T. et al., 1997 & Remove debris \\
\hline Saunders W. P. et al., 1995 & Remove debris \\
\hline Machida T. et al., 1995 & Remove debris, Thermal effects \\
\hline Moshonov J. et al., 1995 & Remove debris \\
\hline Bahcall J. K. et al., 1993 & Remove debris, Morphological \\
\hline Frentzen M. et al., 1991 & Remove debris \\
\hline Liesenhoff T. et al., 1989 & Remove debris, Morphological \\
\hline Pini R. et al., 1989 & Remove debris \\
\hline
\end{tabular}

search, met all the inclusion criteria and 5 or more of the validity assessment criteria. So, they were finally included (Table 6).

\subsection{Embase Search}

The Embase search from 1945 to June 2010 identified 35 articles. From these 35 articles identified by the search, the hand examination of titles, abstracts and articles in full text, revealed that all of them were irrelevant.

In order to be able to compare the bactericidal ability of the various treatment protocols that were applied on the human teeth in vitro, by each different group of researchers, the results were expressed in $\log \mathrm{CFU} / \mathrm{ml}$. The $\mathrm{CFU} / \mathrm{ml}$ of the bacteria that were found in the root canals after bacterial contamination and consecutive standard root canal preparation and/or laser irradiation was calculated and converted in $\log \mathrm{CFU} / \mathrm{ml}$. The closer the value of $\log \mathrm{CFU} / \mathrm{ml}$ is to 0 , the greater the positive effect the treatment protocol has to the root canal disinfecttion.

$\mathrm{Log}$ CFU $/ \mathrm{ml}$ of all bacteria is plotted in Tables 15-23 (Clustered bars and 3-D clustered bars). On the $\mathrm{X}$-axis lies the $\log \mathrm{CFU} / \mathrm{ml}$ and on the Y-axis the various treatment protocols. 
Table 9. Excluded articles: morphological changes.

\begin{tabular}{|c|c|}
\hline Reference & Details \\
\hline Gurbuz, T. et al., 2008 & Morphological study \\
\hline Da Costa Ribeiro, A. et al., 2007 & Morphological, Thermal effects \\
\hline Jahan, K. M. et al., 2006 & Morphological \\
\hline Altundasar, E. et al., 2006 & $\begin{array}{c}\text { Morphological and } \\
\text { Histochemical Changes }\end{array}$ \\
\hline Matsuoka, E. et al., 2005 & Morphological study \\
\hline Biedma, B. M. et al., 2005 & Morphological study \\
\hline Camargo, S. E. et al., 2005 & Morphological study \\
\hline Niccoli-Filho, W. et al., 2005 & Morphological study \\
\hline Ali, M. N. et al., 2005 & $\begin{array}{l}\text { Morphological study, } \\
\text { Smear layer removal }\end{array}$ \\
\hline Ishizaki, N. T. et al., 2004 & Morphological, Thermal effects \\
\hline Khabbaz, M. G. et al., 2004 & Morphological study \\
\hline Kesler, G. et al., 2002 & $\begin{array}{l}\text { Morphological study, } \\
\text { Remove smear layer }\end{array}$ \\
\hline Kaitsas, V. et al., 2001 & $\begin{array}{l}\text { Morphological and } \\
\text { Histological changes }\end{array}$ \\
\hline Matsuoka, E. et al., 2000 & Morphological study \\
\hline Yamazaki, R. et al., 2001 & Morphological, Thermal effects \\
\hline Barbakow, F. et al., 1999 & $\begin{array}{l}\text { Morphological study, } \\
\text { Remove smear layer }\end{array}$ \\
\hline Takeda, F. H. et al., 1999 & $\begin{array}{l}\text { Morphological study, } \\
\text { Remove smear layer }\end{array}$ \\
\hline Eto, J. N. et al., 1999 & $\begin{array}{l}\text { Morphological study, } \\
\text { Remove smear layer }\end{array}$ \\
\hline Takeda, F. H. et al., 1998 & $\begin{array}{l}\text { Morphological study, } \\
\text { Remove smear layer }\end{array}$ \\
\hline Harashima, T. et al., 1998 & $\begin{array}{l}\text { Morphological study, } \\
\text { Remove smear layer }\end{array}$ \\
\hline Khan, M. A. et al., 1997 & Morphological, Thermal effects \\
\hline Komori, T. et al., 1997 & Morphological, Thermal effects \\
\hline Goodis, H. E. et al., 1993 & $\begin{array}{l}\text { Morphological study, } \\
\text { Remove smear layer }\end{array}$ \\
\hline Gutknecht, N., Behrens, V. G. 1991 & Morphological study \\
\hline
\end{tabular}

Table 10. Excluded articles: obturation/apical leakage.

\begin{tabular}{cc} 
Reference & Details \\
\hline Ebihara A. et al., 2002 & Apical leakage after obturation \\
Kimura Y. et al., 1999 & Apical leakage after obturation \\
Kimura Y. et al., 2001 & Apical leakage after obturation \\
Park D. S. et al., 2001 & Apical leakage after obturation \\
Goya C. et al., 2000 & Apical leakage after obturation, \\
Removal of smear layer \\
Yamazaki R. et al., 1999 & Apical leakage after obturation \\
De Moura-Netto C. et al., 2007 & Apical sealing \\
Gekelman D. et al., 2002 & Apical sealing of root canal fillings \\
Carvalho C. A. et al., 2002 & Apical sealing of root canal fillings. \\
Varella C. H., Pillegi R., 2007 & Obturation \\
Gharib S. R. et al., 2007 & Obturation \\
Wang X. et al., 2005 & Obturation, Morphological, \\
& Thermal effects, Apical leakage \\
\hline
\end{tabular}

Table 11. Excluded articles: dentin permeability.

\begin{tabular}{cc}
\hline Reference & Details \\
\hline Winik, R. et al., 2006 & Marginal permeability, Tubular penetration, \\
Al-Azzawi, L. M. et al., 2006 & Dentin permeability \\
Aranha, A. C. et al., 2005 & Dentin permeability \\
Oliveira, R. G. et al., 2004 & Dentin permeability after apicoectomy \\
Gouw-Soares, S. et al., 2004 & Dentin permeability \\
Arisu, H. D. et al., 2004 & Dentin permeability, Morphological \\
Brugnera, A. Jr. et al., 2003 & Dentin permeability \\
Lee, B. S. et al., 2002 & Dentin permeability \\
Pecora, J. D. et al., 2000 & Dentin permeability \\
Stabholz, A. et al., 1992 & Dentin permeability \\
De Souza, F. D. et al., 2005 & Coronal microleakage \\
\hline
\end{tabular}

Table 12. Excluded articles: thermal effects/adhesion of root canal sealers

\begin{tabular}{cc}
\hline Reference & Details \\
\hline Nammour S. et al., 2004 & Thermal effects \\
Deutsch A. S. et al., 2004 & Thermal effects \\
Amyra T. et al., 2000 & Thermal effects, Morphological \\
Cohen B. I. et al., 1996 & Thermal effects \\
Neev J. et al., 1993 & Thermal effects \\
\hline
\end{tabular}

Table 13. Excluded studies: not meeting validity criteria.

\begin{tabular}{|c|c|c|c|c|c|c|c|}
\hline Reference & 1 & 2 & 3 & 4 & 5 & 6 & 7 \\
\hline Fonseca, M. B. et al., 2008 & $\mathrm{~N}$ & $\mathrm{~N}$ & $\mathrm{Y}$ & $\mathrm{Y}$ & $\mathrm{N}$ & $\mathrm{Y}$ & $\mathrm{Y}$ \\
\hline Gordon, W. et al., 2007 & $\mathrm{~N}$ & $\mathrm{~N}$ & $\mathrm{Y}$ & $\mathrm{Y}$ & $\mathrm{N}$ & $\mathrm{Y}$ & $\mathrm{Y}$ \\
\hline Schoop, U. et al., 2007 & $\mathrm{~N}$ & $\mathrm{~N}$ & $\mathrm{Y}$ & $\mathrm{Y}$ & $\mathrm{N}$ & $\mathrm{Y}$ & $\mathrm{Y}$ \\
\hline Soukos, N. S. et al., 2006 & $\mathrm{~N}$ & $\mathrm{~N}$ & $\mathrm{Y}$ & $\mathrm{Y}$ & $\mathrm{N}$ & $\mathrm{Y}$ & $\mathrm{Y}$ \\
\hline Vezzani, M. S. et al., 2006 & $\mathrm{~N}$ & $\mathrm{~N}$ & $\mathrm{Y}$ & $\mathrm{Y}$ & $\mathrm{N}$ & $\mathrm{Y}$ & $\mathrm{Y}$ \\
\hline Perin, F. M. et al., 2004 & $\mathrm{~N}$ & $\mathrm{~N}$ & $\mathrm{Y}$ & $\mathrm{Y}$ & $\mathrm{N}$ & $\mathrm{Y}$ & $\mathrm{Y}$ \\
\hline Kreisler, M. et al., 2003 & $\mathrm{~N}$ & $\mathrm{~N}$ & $\mathrm{Y}$ & $\mathrm{Y}$ & $\mathrm{N}$ & $\mathrm{Y}$ & $\mathrm{Y}$ \\
\hline Dostalov $\alpha$, T. et al., 2002 & $\mathrm{~N}$ & $\mathrm{~N}$ & $\mathrm{Y}$ & $\mathrm{Y}$ & $\mathrm{N}$ & Y & $\mathrm{Y}$ \\
\hline Schoop, U. et al., 2002 & $\mathrm{~N}$ & $\mathrm{~N}$ & Y & $\mathrm{Y}$ & $\mathrm{N}$ & Y & $\mathrm{Y}$ \\
\hline Moritz, A. et al., 1997 & $\mathrm{~N}$ & $\mathrm{~N}$ & $\mathrm{Y}$ & $\mathrm{Y}$ & $\mathrm{N}$ & $\mathrm{Y}$ & $\mathrm{Y}$ \\
\hline Ramskold, L. O. et al., 1997 & $\mathrm{~N}$ & $\mathrm{~N}$ & $\mathrm{Y}$ & $\mathrm{Y}$ & $\mathrm{N}$ & $\mathrm{Y}$ & $\mathrm{Y}$ \\
\hline Gutknecht, N. et al., 1997 & $\mathrm{~N}$ & $\mathrm{~N}$ & $\mathrm{Y}$ & $\mathrm{Y}$ & $\mathrm{N}$ & $\mathrm{Y}$ & Y \\
\hline Moshonov, J. et al., 1995 & $\mathrm{~N}$ & $\mathrm{~N}$ & $\mathrm{Y}$ & Y & $\mathrm{N}$ & $\mathrm{Y}$ & Y \\
\hline Fegan, S. E. et al., 1995 & $\mathrm{~N}$ & $\mathrm{~N}$ & $\mathrm{Y}$ & $\mathrm{Y}$ & $\mathrm{N}$ & Y & $\mathrm{Y}$ \\
\hline Hardee, M. W. et al., 1994 & $\mathrm{~N}$ & $\mathrm{~N}$ & $\mathrm{Y}$ & $\mathrm{Y}$ & $\mathrm{N}$ & Y & $\mathrm{Y}$ \\
\hline
\end{tabular}

A) Analysis of the Results of Studies with Specific Bacteria

- Enterococcus faecalis

Enterococcus faecalis survival was examined 19 times by 5 different groups of researchers. 
Table 14. Analysis of treatment protocols.

\begin{tabular}{|c|c|c|c|c|c|c|}
\hline $\begin{array}{l}\text { REFERENCES/ } \\
\text { BACTERIA }\end{array}$ & $\begin{array}{c}\text { STORAGE } \\
\text { MATERIAL }\end{array}$ & $\begin{array}{l}\text { IRRIGATION } \\
\text { SOLUTION }\end{array}$ & INSTRUMENTATION & LASER & DURATION & $\begin{array}{l}\text { NUMBER } \\
\text { OF TEETH }\end{array}$ \\
\hline 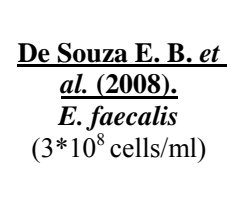 & $1 \% \mathrm{NaOCl}$ & $\begin{array}{l}\quad \mathrm{G} 1, \mathrm{G} 2: \\
0.5 \% \mathrm{NaOCl}+\text { urea } \\
\text { peroxide cream }+ \\
17 \% \text { EDTA-T }+ \\
\text { saline solution } \mathrm{G} 3: \\
\text { Saline solution }\end{array}$ & $\begin{array}{c}\text { G1, G2,: Rotary } \\
\text { instrumentation } \\
\text { (Crown down), No } 50 .\end{array}$ & $\begin{array}{l}\text { G1: diode laser }(830 \mathrm{~nm} / 3 \mathrm{~W}) \\
\text { G2: no laser irradiation } \\
\text { G3: no laser irradiation } \\
\text { (control) }\end{array}$ & 2 days & $\begin{aligned} \mathrm{N} & =30 \\
\mathrm{G} 1 & =10 \\
\mathrm{G} 2 & =10 \\
\mathrm{G} 3 & =10\end{aligned}$ \\
\hline $\begin{array}{c}\text { Fimple } \mathbf{~} \text {. L. et al. } \\
\underline{(2008)} \\
\text { A. israelii } \\
\left(2.5^{*} 10^{8} \text { cells } / \mathrm{ml}\right) \\
\text { F. } \text { nucleatum } \\
\left(2.5^{*} 10^{8} \text { cells } / \mathrm{ml}\right) \\
\text { P. gingivalis } \\
\left(2.5^{*} 10^{8} \text { cells } / \mathrm{ml}\right) \\
\text { P. } \text { intermedia } \\
\left(2.5^{*} 10^{8} \text { cells } / \mathrm{ml}\right)\end{array}$ & $\begin{array}{l}0.5 \% \mathrm{NaOCl} \text { for } \\
2-4 \\
\text { weeks. } \\
\end{array}$ & $\begin{array}{c}\text { G1 - G4: } \\
\text { RcPrep }+ \\
6 \% \mathrm{NaOCl}+ \\
17 \% \mathrm{EDTA}+ \\
6 \% \mathrm{NaOCl}\end{array}$ & $\begin{array}{l}\text { G1 - G4: } \\
\text { Rotary instrumentation } \\
\text { (Crown-down) } \\
\text { MAF: } 0.465\end{array}$ & $\begin{array}{c}\frac{\text { First set of experiments }}{(\mathrm{n}=72, \text { BHI broth }):} \\
\text { G1: No laser/No MB } \\
\text { G2: MB only } \\
\text { G3: Diode laser } \\
(665 \mathrm{~nm} / 1 \mathrm{~W}) \\
\text { G4: Diode laser }(665 \mathrm{~nm} / 1 \mathrm{~W}) \\
\text { and MB } \\
\text { Second set of experiments } \\
\text { (n }=39, \text { PBS broth): } \\
\text { G1: No laser/No MB } \\
\text { G2: MB only } \\
\text { G3: Diode laser } \\
(665 \mathrm{~nm} / 1 \mathrm{~W}) \text { and } \mathrm{MB}\end{array}$ & 7 days & 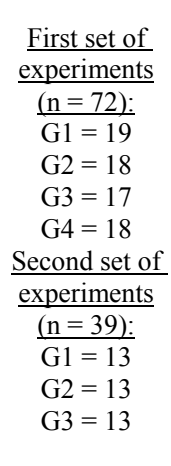 \\
\hline $\begin{array}{c}\text { Bergmans L. et al. } \\
\begin{array}{c}\text { S. } \text { anginosus } \\
\left(4 * 10^{8} \text { cells } / \mathrm{ml}\right)\end{array}\end{array}$ & $\begin{array}{c}0.5 \% \text { chloramine } \\
\text { in water at } \\
4^{\circ} \mathrm{C}\end{array}$ & $\begin{array}{l}\text { Ga - Gd: } \\
2.5 \% \mathrm{NaOCl}+ \\
17 \% \mathrm{EDTA}+\text { tap } \\
\text { water }\end{array}$ & $\begin{array}{l}\text { Ga-Gd: } \\
\text { Rotary instrumentation } \\
\text { (Crown down), No } 30 .\end{array}$ & $\begin{array}{c}\text { Ga: diode laser }(635 \mathrm{~nm} / 0.1 \mathrm{~W})+ \\
\text { TBO }+ \text { RTF } \\
\text { Gb: diode laser }(635 \mathrm{~nm} / 0.1 \mathrm{~W})+ \\
\text { RTF } \\
\text { Gc: TBO + RTF } \\
\text { Gd: RTF (positive control) }\end{array}$ & 2 days & $\begin{array}{l}\mathrm{N}=12 \\
\mathrm{Ga}=3 \\
\mathrm{~Gb}=3 \\
\mathrm{Gc}=3 \\
\mathrm{Gd}=3\end{array}$ \\
\hline $\begin{array}{c}\text { E. faecalis: } \\
\left(4 * 10^{8} \text { cells } / \mathrm{ml}\right)\end{array}$ & $\begin{array}{c}0.5 \% \text { chloramine } \\
\text { in water at } \\
4^{\circ} \mathrm{C}\end{array}$ & $\begin{array}{l}\text { Ga - Gd: } \\
2.5 \% \mathrm{NaOCl}+ \\
17 \% \mathrm{EDTA}+\text { tap } \\
\text { water }\end{array}$ & $\begin{array}{l}\text { Ga-Gd: } \\
\text { Rotary instrumentation } \\
\text { (Crown down), No } 30 .\end{array}$ & $\begin{array}{c}\text { Ga: diode laser }(635 \mathrm{~nm} / 0.1 \mathrm{~W}) \\
+ \text { TBO }+ \text { RTF } \\
\text { Gb: diode laser }(635 \mathrm{~nm} / 0.1 \mathrm{~W}) \\
+ \text { RTF } \\
\text { Gc: TBO + RTF } \\
\text { Gd: RTF (positive control) }\end{array}$ & 2 days & $\begin{array}{l}\mathrm{N}=12 \\
\mathrm{Ga}=3 \\
\mathrm{~Gb}=3 \\
\mathrm{Gc}=3 \\
\mathrm{Gd}=3\end{array}$ \\
\hline $\begin{array}{c}\text { F. } \text { nucleatum } \\
\left(4 * 10^{8} \text { cells } / \mathrm{ml}\right)\end{array}$ & $\begin{array}{c}0.5 \% \text { chloramine } \\
\text { in water at } \\
4^{\circ} \mathrm{C} \text {. }\end{array}$ & $\begin{array}{c}\text { Ga - Gd: } \\
2.5 \% \mathrm{NaOCl}+ \\
17 \% \mathrm{EDTA}+\text { tap } \\
\text { water }\end{array}$ & $\begin{array}{l}\text { Ga - Gd: } \\
\text { Rotary instrumentation } \\
\text { (Crown down), No } 30 .\end{array}$ & $\begin{array}{c}\text { Ga: diode laser }(635 \mathrm{~nm} / 0.1 \mathrm{~W}) \\
+ \text { TBO }+ \text { RTF } \\
\text { Gb: diode laser }(635 \mathrm{~nm} / 0.1 \mathrm{~W}) \\
+ \text { RTF } \\
\text { Gc: TBO + RTF } \\
\text { Gd: RTF (positive control) }\end{array}$ & 2 days & $\begin{array}{l}\mathrm{N}=12 \\
\mathrm{Ga}=3 \\
\mathrm{~Gb}=3 \\
\mathrm{Gc}=3 \\
\mathrm{Gd}=3\end{array}$ \\
\hline$\frac{\text { Negative group }}{\text { (uninfected) }}$ & $\begin{array}{c}0.5 \% \text { chloramine } \\
\text { in water at } \\
4^{\circ} \mathrm{C}\end{array}$ & $\begin{array}{l}\text { Ga - Gd: } \\
2.5 \% \mathrm{NaOCl}+ \\
17 \% \text { EDTA + tap } \\
\text { water }\end{array}$ & $\begin{array}{l}\text { Ga - Gd: } \\
\text { Rotary instrumentation } \\
\text { (Crown down), No } 30 .\end{array}$ & No laser & 2 days & $\mathrm{N}=2$ \\
\hline $\begin{array}{c}\frac{\text { Foschi F., et al. }}{\underline{(2007)}} \\
\text { E. faecalis } \\
\left(5^{*} 10^{8} \text { cells }\right)\end{array}$ & $\begin{array}{c}0.5 \% \mathrm{NaOCl} \text { for } \\
2 \text { weeks. }\end{array}$ & $\begin{array}{c}\text { G1 - G4 } \\
6 \% \mathrm{NaOCl}: \\
17 \% \text { EDTA } \\
\text { deactivated with } \\
6 \% \mathrm{NaOCl} \text { for } 3 \\
\text { min. }\end{array}$ & $\begin{array}{l}\text { G1 - G4 } \\
\text { Rotary instrumentation } \\
\text { (Crown down), } \\
\text { MAF: } 0.465\end{array}$ & $\begin{array}{c}\text { G1: no laser/no MB } \\
\text { G2: MB } \\
\text { G3: Diode laser }(665 \mathrm{~nm} / 1 \mathrm{~W}) \\
\text { G4: Diode laser }(665 \mathrm{~nm} / 1 \mathrm{~W}) \\
\text { and } \mathrm{MB}\end{array}$ & 6 days & $\begin{aligned} \mathrm{N} & =64 \\
\mathrm{G} 1 & =15 \\
\mathrm{G} 2 & =15 \\
\mathrm{G} 3 & =15 \\
\mathrm{G} 4 & =15\end{aligned}$ \\
\hline$\frac{\text { Wang Q.et al. }}{\underline{\text { (2007) }}}$ & $\begin{array}{l}\text { physiological } \\
\text { saline solution at } \\
4^{\circ} \mathrm{C}\end{array}$ & $\begin{array}{c}\frac{\mathrm{G} 1-\mathrm{G} 4:}{5.25 \% \mathrm{NaOCl}+} \\
\text { physiological saline } \\
\text { G5: } \\
2.5 \% \mathrm{NaOCl}+ \\
5.25 \% \mathrm{NaHS}+ \\
\text { physiological saline } \\
\underline{\text { G6: }} \\
\text { None }\end{array}$ & $\begin{array}{l}\frac{\mathrm{G} 1-\mathrm{G} 6:}{\text { Hand instrumentation }} \\
\text { (step-back), No } 50\end{array}$ & $\begin{array}{l}\text { G1: Er,Cr:YSGG }(2780 \mathrm{~nm} / 1 \mathrm{~W}) \\
\text { G2: Er,Cr:YSGG }(2780 \mathrm{~nm} / 1.5 \mathrm{~W}) \\
\text { G3: Nd:YAG }(1064 \mathrm{~nm} / 1 \mathrm{~W}) \\
\text { G4: Nd:YAG }(1064 \mathrm{~nm} / 1.5 \mathrm{~W}) \\
\text { G5: no laser irradiation } \\
\text { (positive control) } \\
\text { G6: no laser irradiation } \\
\text { (negative control) }\end{array}$ & 1 day & $\begin{aligned} \mathrm{N} & =60 \\
\mathrm{G} 1 & =10 \\
\mathrm{G} 2 & =10 \\
\mathrm{G} 3 & =10 \\
\mathrm{G} 4 & =10 \\
\mathrm{G} 5 & =10 \\
\mathrm{G} 6 & =10\end{aligned}$ \\
\hline
\end{tabular}




\begin{tabular}{|c|c|c|c|c|c|c|}
\hline $\begin{array}{c}\text { Bergmans L., et al. } \\
\underline{\text { E. faecalis }} \\
\left(4 * 10^{8} \mathrm{CFU} / \mathrm{ml}\right)\end{array}$ & $\begin{array}{l}0.5 \% \text { chloramine } \\
\text { in water } \\
\text { at } 4^{\circ} \mathrm{C}\end{array}$ & $\begin{array}{c}\text { G1, G2: } \\
2.5 \% \mathrm{NaOCl}+ \\
17 \% \mathrm{EDTA}+ \\
\text { tap water }+0.9 \% \\
\text { sterile saline } \\
\text { G3: } \\
2.5 \% \mathrm{NaOCl}+ \\
17 \% \mathrm{EDTA}+ \\
\text { tap water }\end{array}$ & $\begin{array}{l}\text { G1 - G3: } \\
\text { Rotary instrumentation } \\
\text { (Crown down), No } 30\end{array}$ & $\begin{array}{l}\text { G1: Nd:YAG laser } \\
\text { (1064 nm/1.5 W/15 Hz) + RTF } \\
\text { G2: RTF, no laser irradiation, } \\
\text { Infected (positive control) } \\
\text { G3: RTF, no laser irradiation, } \\
\text { (uninfected, negative control) }\end{array}$ & 2 days & $\begin{array}{l}\mathrm{N}=8 \\
\mathrm{G} 1=3 \\
\mathrm{G} 2=3 \\
\mathrm{G} 3=2\end{array}$ \\
\hline $\begin{array}{l}\frac{\text { Piccolomini R., et }}{\text { al. (2002) }} \\
\text { A. naeslundii } \\
\left(1.8^{*} 10^{8} \mathrm{CFU} / \mathrm{ml}\right)\end{array}$ & none & $\begin{array}{c}\frac{\text { SubA, SubB1, }}{\text { SubB2 }} \\
\text { Physiological } \\
\text { saline + EDTA } \\
\text { SubC: } \\
\text { physiological } \\
\text { saline + } \\
\text { EDTA + } \\
5.25 \% \mathrm{NaOCl}\end{array}$ & $\begin{array}{l}\frac{\text { All groups: }}{\text { Hand instrumentation }} \\
\text { (Crown-down). }\end{array}$ & $\begin{array}{c}\text { SubA: no laser irradiation } \\
\text { (control) } \\
\text { SubB1: Nd:YAG laser } \\
\text { (1064 nm/5 Hz) } \\
\text { Sub B2: Nd:YAG laser } \\
\text { (1064 nm/10 Hz) } \\
\text { SubC: no laser irradiation }\end{array}$ & 1 day. & $\begin{aligned} & \underline{\mathrm{N}}=60 \\
& \mathrm{SubA}=5 \\
& \mathrm{SubB} 1=10 \\
& \mathrm{SubB} 2=10 \\
& \mathrm{SubC}=5\end{aligned}$ \\
\hline $\begin{array}{c}\text { P. aeruginosa } \\
\left(1.8^{*} 10^{8} \mathrm{CFU} / \mathrm{ml}\right)\end{array}$ & none & $\begin{array}{c}\frac{\text { SubA, SubB1, }}{\text { SubB2 }} \\
\text { Physiological } \\
\text { saline + EDTA } \\
\text { SubC: } \\
\text { physiological } \\
\text { saline+ } \\
\text { EDTA+ } \\
5.25 \% \mathrm{NaOCl}\end{array}$ & $\begin{array}{l}\text { All groups: } \\
\text { Hand instrumentation } \\
\text { (Crown-down). }\end{array}$ & $\begin{array}{c}\text { SubA: no laser irradiation } \\
\text { (control) } \\
\text { SubB1:Nd:YAG laser } \\
\text { (1064 nm/5 Hz) } \\
\text { Sub B2: Nd:YAG laser } \\
\text { (1064 nm/10 Hz) } \\
\text { SubC: no laser irradiation }\end{array}$ & 1 day. & $\begin{aligned} \text { SubA } & =5 \\
\text { SubB1 } & =10 \\
\text { SubB2 } & =10 \\
\text { SubC } & =5\end{aligned}$ \\
\hline $\begin{array}{l}\frac{\text { Folwaczny M., et }}{\text { al. (2002) }} \\
\text { Escherichia Coli } \\
\left(8.67^{*} 10^{6}\right. \\
\text { CFU } / \mathrm{ml})\end{array}$ & $\begin{array}{l}\text { Sterile saline } \\
\text { solution }\end{array}$ & $\begin{array}{l}\text { G1a-G1d: saline } \\
\text { solution } \\
\text { G1d; } \\
\text { saline solution+ } \\
1 \% \mathrm{NaOCl}\end{array}$ & $\begin{array}{c}\text { G1a-G1d: } \\
\text { Hand instrumentation, } \\
\text { No } 40 .\end{array}$ & $\begin{array}{l}\text { G1a:No laser irradiation } \\
\text { (positive control) } \\
\text { G1b: Nd:YAG laser } \\
\text { (1064 nm/0.005 W) } \\
\text { G1c: Nd:YAG laser } \\
\text { (1064 nm/0.01 W) } \\
\text { G1d: No laser irradiation }\end{array}$ & 1 day & $\begin{array}{l}\mathrm{N}=114 \\
\mathrm{G} 1 \mathrm{a}=13 \\
\mathrm{G} 1 \mathrm{~b}=13 \\
\mathrm{G} 1 \mathrm{c}=13 \\
\mathrm{G} 1 \mathrm{~d}=13\end{array}$ \\
\hline $\begin{array}{l}\frac{\text { Folwaczny M., et }}{\text { al. }(2002)} \\
\begin{array}{c}\text { S. aureus } \\
\left(1.44 * 10^{6} \mathrm{CFU} / \mathrm{ml}\right)\end{array}\end{array}$ & $\begin{array}{l}\text { Sterile saline } \\
\text { solution }\end{array}$ & $\begin{array}{l}\text { G2a-G2d: saline } \\
\text { solution } \\
\text { G2d; } \\
\text { saline solution }+ \\
1 \% \mathrm{NaOCl}\end{array}$ & $\begin{array}{c}\text { Hand instrumentation, } \\
\text { No } 40 .\end{array}$ & $\begin{array}{l}\text { G2a:No laser irradiation } \\
\text { (positive control) } \\
\text { G2b: Nd:YAG laser } \\
(1064 \mathrm{~nm} / 0.005 \mathrm{~W}) \\
\text { G2c: Nd:YAG laser } \\
(1064 \mathrm{~nm} / 0.01 \mathrm{~W}) \\
\text { G2d: No laser irradiation }\end{array}$ & 1 day & $\begin{array}{l}\mathrm{G} 2 \mathrm{a}=13 \\
\mathrm{G} 2 \mathrm{~b}=13 \\
\mathrm{G} 2 \mathrm{c}=13 \\
\mathrm{G} 2 \mathrm{~d}=13\end{array}$ \\
\hline $\begin{array}{l}\text { Negative control } \\
\quad \text { (uninfected) }\end{array}$ & $\begin{array}{l}\text { Sterile saline } \\
\text { solution }\end{array}$ & saline solution & $\begin{array}{l}\text { Hand instrumentation, } \\
\text { No } 40 .\end{array}$ & $\begin{array}{l}\text { G3: no laser irradiation } \\
\text { (negative control) }\end{array}$ & 1 day & $\mathrm{G} 3=10$ \\
\hline $\begin{array}{l}\frac{\text { Moritz A., et al. }}{(1999)} \\
\begin{array}{c}\text { Escherichia coli } \\
\text { and }\end{array} \\
\begin{array}{c}\text { Enterococcus fae- } \\
\text { calis }\end{array} \\
\left(5 * 10^{5} \mathrm{CFU} / \mathrm{mL}\right)\end{array}$ & $\begin{array}{l}\text { Physiological } \\
\text { saline solution }\end{array}$ & $\begin{array}{l}\text { All groups: } \\
\text { EDTA+ physio- } \\
\text { logical saline } \\
\text { solution }\end{array}$ & $\begin{array}{l}\text { All groups: } \\
\text { Rotary instrumentation, } \\
\text { (Step-back) }\end{array}$ & $\begin{array}{c}\text { G1: Positive control (untreated) } \\
\text { G2: Nd:YAG laser } \\
\text { (0.8 W/1064 nm) } \\
\text { G3: Nd:YAG laser } \\
\text { (1.5 W/1064 nm) } \\
\text { G4: Ho: YAG laser } \\
\text { (0.8 W/2130 nm) } \\
\text { G5: Ho:YAG laser, } \\
\text { (1.5 W/2130 nm) } \\
\text { G6: Er:YAG laser, } \\
\text { (0.8 W/2940 nm) } \\
\text { G7: Er:YAG laser, } \\
\text { (1.5 W/2940 nm) }\end{array}$ & 1 day & $\begin{array}{l}\mathrm{N}=40 \\
\mathrm{G} 1: 10 \\
\mathrm{G} 2: 5 \\
\mathrm{G} 3: 5 \\
\text { G4: } 5 \\
\text { G5: } 5 \\
\text { G6: } 5 \\
\text { G7: } 5\end{array}$ \\
\hline $\begin{array}{c}\frac{\text { Mehl A., et al. }}{\underline{(1999)}} \\
\text { Escherichia coli } \\
\left(1.1 * 10^{6} \mathrm{CFU} / \mathrm{ml}\right)\end{array}$ & none & $\begin{array}{c}\text { Ge1-Ge4: sterile } \\
\text { saline solution } \\
\text { Ge4: } \\
1.25 \% \\
\mathrm{NaOCl}\end{array}$ & $\begin{array}{l}\text { Hand instrumentation, } \\
\text { No } 40 \text {. }\end{array}$ & $\begin{array}{c}\text { Gs1: no laser irradiation } \\
\text { (positive control) } \\
\text { Gs2: Er:YAG } \\
(2940 \mathrm{~nm} / 0.003 \mathrm{~W} / 15 \mathrm{sec} / 50 \mathrm{~mJ}) \\
\text { Gs3: Er:YAG } \\
(2940 \mathrm{~nm} / 0.001 \mathrm{~W} / 60 \mathrm{sec} / 50 \mathrm{~mJ}) \\
\text { Gs4: no laser irradiation } \\
(1.25 \% \mathrm{NaOCl})\end{array}$ & 1 day & $\begin{array}{l}\mathrm{N}=90 \\
\text { Ge1: } 10 \\
\text { Ge2: } 10 \\
\text { Ge3: } 10 \\
\text { Ge4: } 10\end{array}$ \\
\hline
\end{tabular}




\begin{tabular}{|c|c|c|c|c|c|c|}
\hline $\begin{array}{c}\text { S. aureus } \\
\left(1.53 * 10^{6} \mathrm{CFU} / \mathrm{ml}\right)\end{array}$ & none & $\begin{array}{c}\text { Gs1-Gs4: sterile } \\
\text { saline solution } \\
\text { Gs4: } \\
1.25 \% \mathrm{NaOCl}\end{array}$ & $\begin{array}{l}\text { Hand instrumentation, } \\
\text { No } 40 .\end{array}$ & $\begin{array}{c}\text { Gs 1:no laser irradiation } \\
\text { (positive control) } \\
\text { Gs2: Er:YAG } \\
(2940 \mathrm{~nm} / 0.003 \mathrm{~W} / 15 \mathrm{sec} / 50 \mathrm{~mJ}) \\
\text { Gs3:Er:YAG } \\
(2940 \mathrm{~nm} / 0.001 \mathrm{~W} / 60 \mathrm{sec} / 50 \mathrm{~mJ}) \\
\text { Gs4: no laser irradiation } \\
(1.25 \% \mathrm{NaOCl})\end{array}$ & 1 day & $\begin{array}{l}\text { Gs } 1: 10 \\
\text { Gs2: } 10 \\
\text { Gs3: } 10 \\
\text { Gs4: } 10\end{array}$ \\
\hline $\begin{array}{l}\text { Negative control } \\
\text { (uninfected) }\end{array}$ & none & None & $\begin{array}{l}\text { Hand instrumentation, } \\
\text { No } 40 .\end{array}$ & $\begin{array}{l}\text { Gn: negative } \\
\text { (uninfected) }\end{array}$ & 1 day & Gn: 10 \\
\hline
\end{tabular}

Table 15. Enterococcus faecalis survival.

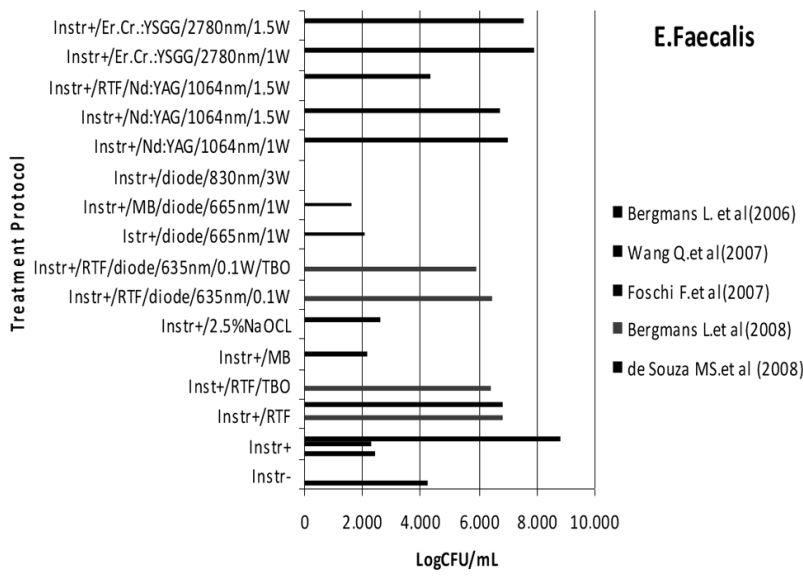

Table 16. Streptococcus anginosus survival.

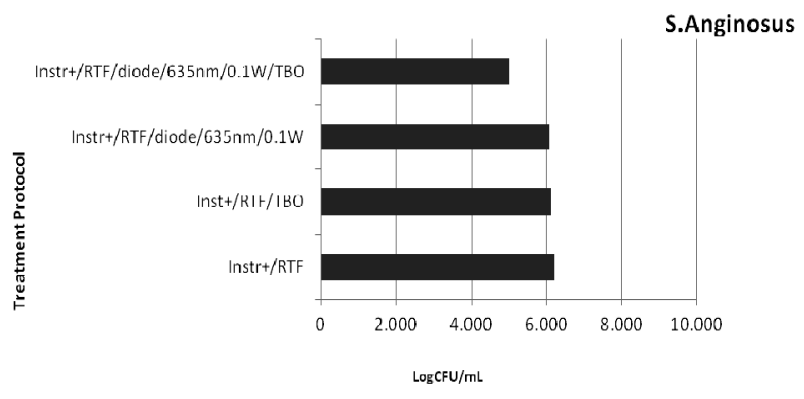

Table 17. Fusobacterium nucleatum survival.

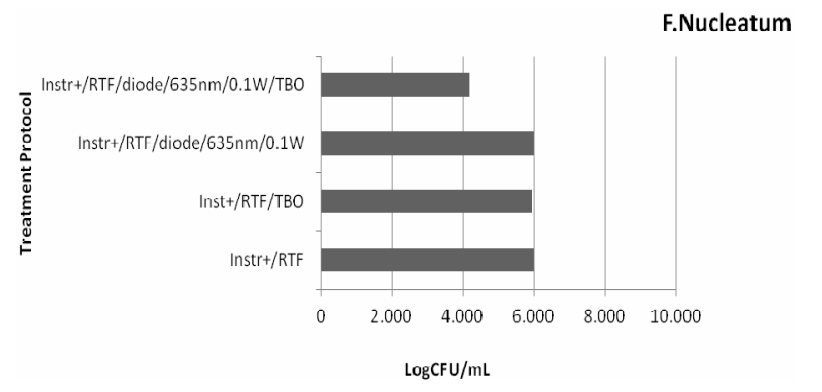

In the first place, they contaminated the root canals with E. faecalis. In the second place they performed chemo-mechanical preparation and/or laser irradiation with or without specific solutions. The $\log C F U / m l$ ranges from 1.636 to 8.818 (Table 15).
Table 18. Escherichia coli survival.

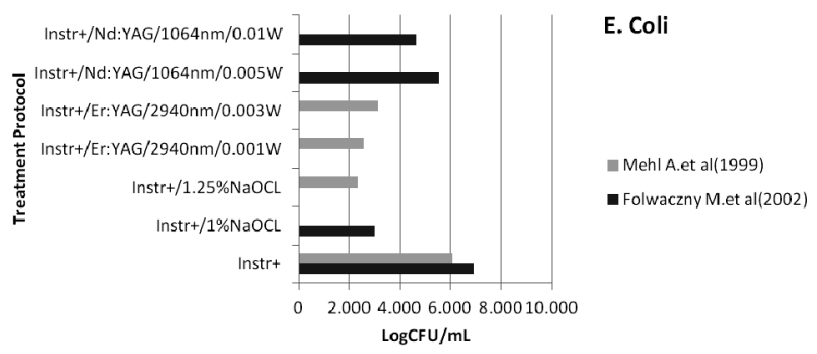

Table 19. Actinomyces naeslundii survival.

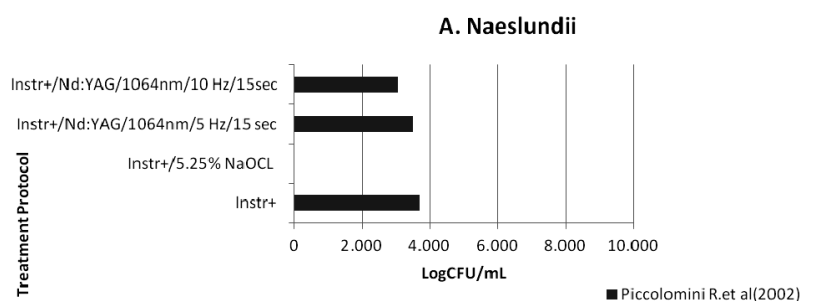

Table 20. Staphylococcus aureus survival.

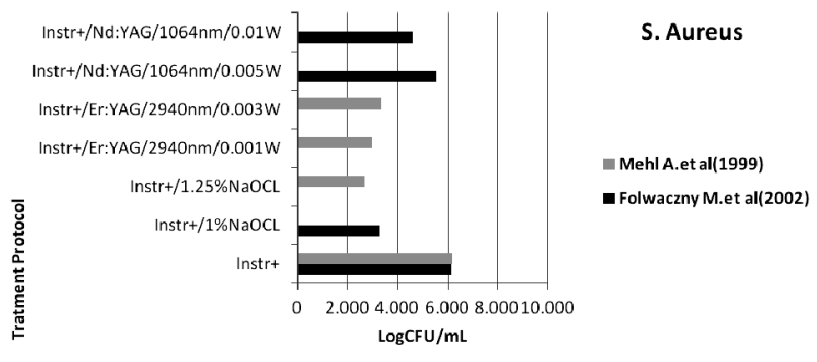

Table 21. Pseudomonas aeruginosa survival.

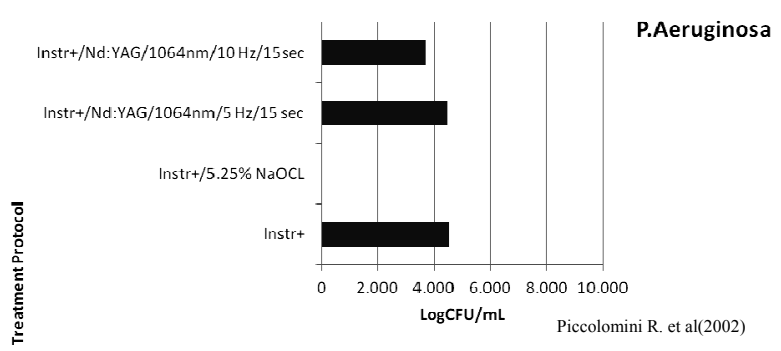

The best treatment protocols for root canal disinfecttion in descending order are as follows:

Instrumentation of the root canal and diode laser/665 nanometer/1 Watt irradiation with the combined effect 
Table 22. Polymicrobial survival.

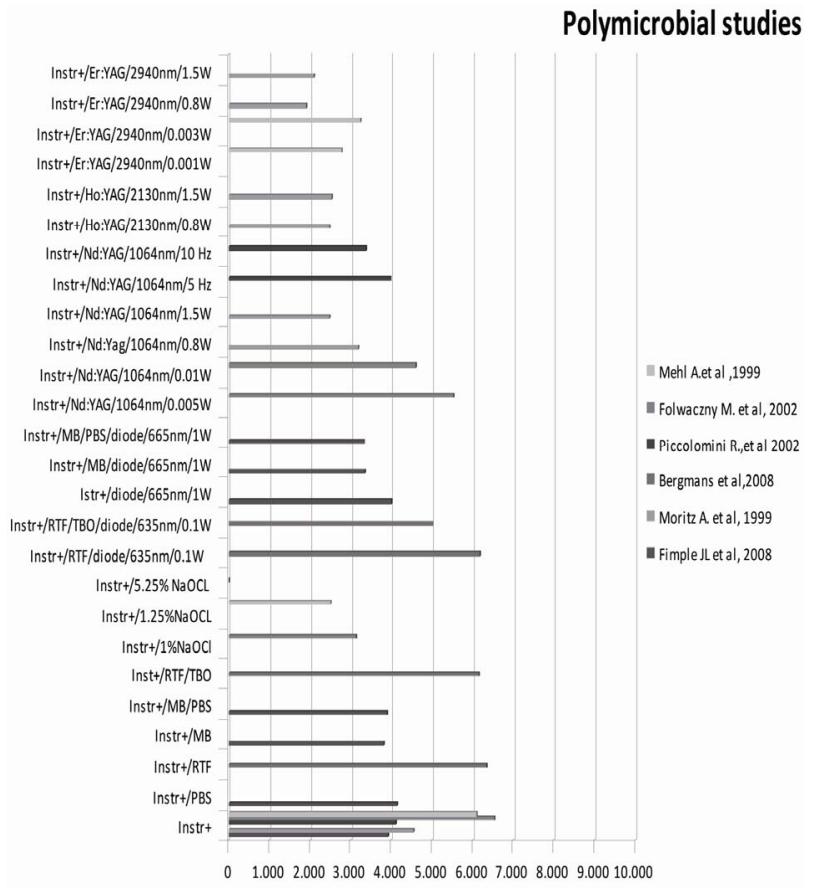

Table 23. Mean microbial survival.

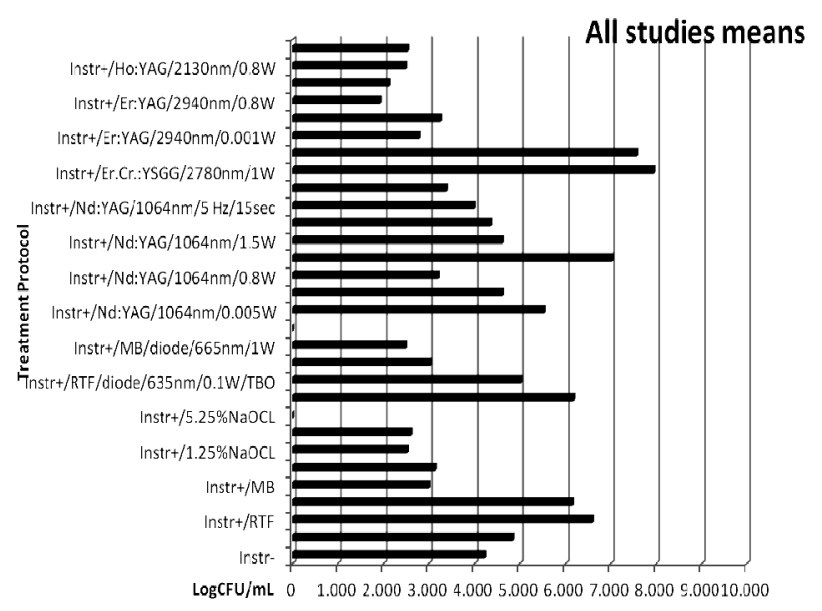

of Methylene Blue (MB) as photosensitizing agent (log$\mathrm{CFU} / \mathrm{ml}=1.636)[33]$.

Instrumentation of the root canal and diode laser/665 $\mathrm{nm} / 1 \mathrm{~W}$ irradiation

$(\log \mathrm{CFU} / \mathrm{ml}=2.061)[33]$.

Instrumentation of the root canal combined with $\mathrm{MB}$ as photosensitizing agent $(\log \mathrm{CFU} / \mathrm{ml}=2.190)$ [33]

Instrumentation followed by irrigation with $2.5 \%$ $\mathrm{NaOCl}$ (sodium hypochloride)

$(\log \mathrm{CFU} / \mathrm{ml}=2.602)[31]$.

When instrumentation and diode laser $/ 830 \mathrm{~nm} / 3 \mathrm{~W}$ were used, no CFU/ml was found. However, as the author explained, this result is due to the fact that the level of sensitivity of the methodology used, was insufficient for detecting viable cells in low concentrations (contact with the author via e-mail) [32].

- Streptococcus anginosus

Streptococcus anginosus survival was examined 4 times by 1 group of researchers. In the first place they performed chemo-mechanical preparation and in the second place they contaminated the root canals with S. anginosus. Consequently, they completed root canal preparation and either used or not laser irradiation with specific solutions. The $\log$ CFU/ml ranges from 5.000 to 6.204 (Table 16) [30].

These results demonstrate no satisfying reduction of $\mathrm{S}$. anginosus after diode laser/635 nm/0.1 W irradiation combined with RTF (reduced transferred fluid) and/or TBO (toluidine blue), nor after instrumentation and irrigation with RTF and/or TBO $(\log \mathrm{CFU} / \mathrm{ml}>5.000)$.

\section{- Fusobacterium nucleatum}

Fusobacterium nucleatum survival was examined 4 times by 1 group of researchers. In the first place they performed chemo-mechanical preparation and in the second place they contaminated the root canals with $F$. nucleatum. Consequently, they completed root canal preparation and either used or not laser irradiation with specific solutions. The $\log \mathrm{CFU} / \mathrm{ml}$ ranges from 4.176 to 6.000 (Table 17) [30].

These results demonstrate no satisfying reduction of F.nucleatum after diode laser/635 nm/0.1 W irradiation combined with RTF (reduced transferred fluid) and/or TBO (toluidine blue), nor after instrumentation and irrigation with RTF and /or TBO ( $\log \mathrm{CFU} / \mathrm{ml}>4.176)$.

\section{- Escherichia coli}

Escherichia coli survival was examined 8 times by 2 different groups of researchers. In the first place they performed chemo-mechanical preparation and in the second place they contaminated the root canals with E. coli. Consequently, they completed root canal preparation and either used or not laser irradiation with or without specific solutions. The logCFU/ml ranges from 2.342 to 6.938 (Table 18).

The best treatment protocols for root canal disinfecttion in descending order are as follows:

Instrumentation of the root canal followed by irrigation with $1.25 \% \mathrm{NaOCl}$

$(\log \mathrm{CFU} / \mathrm{ml}=2.342)[28]$.

Instrumentation of the root canal and Er:YAG laser/ $2,940 \mathrm{~nm} / 0.001 \mathrm{~W}$ irradiation

$(\log \mathrm{CFU} / \mathrm{ml}=2.572)[28]$.

Instrumentation of the root canal followed by irrigation with $1 \% \mathrm{NaOCl}$

$(\log \mathrm{CFU} / \mathrm{ml}=3.012)[25]$.

Instrumentation of the root canal and Er:YAG laser/2940 $\mathrm{nm} / 0.003 \mathrm{~W}$ irradiation $\quad(\log \mathrm{CFU} / \mathrm{ml}=3.155)[28]$. 


\section{- Actinomyces naeslundii}

Actinomyces naeslundii survival was examined 4 times by 1 group of researchers. In the first place they performed chemo-mechanical preparation and in the second place they contaminated the root canals with A. naeslundii. Consequently, they completed root canal preparation and either used or not laser irradiation with or without specific solutions. The $\log \mathrm{CFU} / \mathrm{ml}$ ranges from 0 to 3.698 (Table 19) [29].

The best treatment protocols for root canal disinfection in descending order are as follows:

Instrumentation of the root canal followed by irrigation with $5.25 \% \mathrm{NaOCl}(\log \mathrm{CFU} / \mathrm{ml}=0)$.

Instrumentation of the root canal and Nd:YAG laser/ $1064 \mathrm{~nm} / 10 \mathrm{~Hz} / 15 \mathrm{sec}$ irradiation $(\log \mathrm{CFU} / \mathrm{ml}=3.053)$.

Instrumentation of the root canal and Nd:YAG laser/ $1064 \mathrm{~nm} / 5 \mathrm{~Hz} / 15 \mathrm{sec}$ irradiation ( $\log \mathrm{CFU} / \mathrm{ml}=3.518)$.

Instrumentation of the root canal solely $(\log \mathrm{CFU} / \mathrm{ml}=$ 3.698).

\section{- Staphylococcus aureus}

Staphylococcus aureus survival was examined 8 times by 2 groups of researchers. In the first place they performed chemo-mechanical preparation and in the second place they contaminated the root canals with S.aureus. Consequently, they completed root canal preparation and either used or not laser irradiation with or without specific solutions. The $\log \mathrm{CFU} / \mathrm{ml}$ ranges from 2.703 to 6.184 (Table 20).

The best treatment protocols for root canal disinfection in descending order are as follows:

Instrumentation of the root canal followed by irrigation with $1.25 \% \mathrm{NaOCl}$

$(\log \mathrm{CFU} / \mathrm{ml}=2.703)[28]$.

Instrumentation of the root canal and Er:YAG laser/ $2940 \mathrm{~nm} / 0.001 \mathrm{~W}$ irradiation $(\log \mathrm{CFU} / \mathrm{ml}=2.973)$ [28].

Instrumentation of the root canal followed by irrigation with $1 \% \mathrm{NaOCl}$

$(\log \mathrm{CFU} / \mathrm{ml}=3.246)[25]$.

Instrumentation of the root canal and Er:YAG laser/ $2940 \mathrm{~nm} / 0.003 \mathrm{~W}$ irradiation $(\log \mathrm{CFU} / \mathrm{ml}=3.348)$ [28].

\section{- Pseudomonas aeruginosa}

Pseudomonas aeruginosa survival was examined 4 times by 1 group of researchers. In the first place they performed chemo-mechanical preparation and in the second place they contaminated the root canals with $P$. aeruginosa. Consequently, they completed root canal preparation and either used or not laser irradiation with or without specific solutions. The $\log \mathrm{CFU} / \mathrm{ml}$ ranges from 0 to 4.544 (Table 21) [29].

The best treatment protocols for root canal disinfection in descending order are as follows:

Instrumentation of the root canal followed by irrigation with $5.25 \% \mathrm{NaOCl}(\log \mathrm{CFU} / \mathrm{ml}=0)$.

Instrumentation of the root canal and Nd: YAG laser/
$1064 \mathrm{~nm} / 10 \mathrm{~Hz} / 15 \mathrm{sec}$ irradiation $(\log \mathrm{CFU} / \mathrm{ml}=3.695)$.

\section{B) Analysis of the Polymicrobial Studies Results}

Microbial survival after polymicrobial infection of root canals was examined 30 times by 6 groups of researchers. In the first place they performed chemo-mechanical preparation and in the second place they contaminated the root canals with some of the following microorganisms; E. coli, S. aureus, A. naeslundii, P. aeruginosa, S. anginosus, E. faecalis, F. nucleatum, A. israelii, $P$. gingivalis and $P$. intermedia. Consequently, they completed root canal preparation and either used or not laser irradiation with or without specific solutions. The log$\mathrm{CFU} / \mathrm{ml}$ ranges from 0 to 6.548 (Table 22).

The best treatment protocols for root canal disinfection in descending order are as follows:

Instrumentation of the root canal followed by irrigation with $5.25 \% \mathrm{NaOCl}(\log \mathrm{CFU} / \mathrm{ml}=0)$ [29].

Instrumentation of the root canal and Er:YAG laser/ $2940 \mathrm{~nm} / 0.8 \mathrm{~W}$ irradiation

$(\log C F U / m l=1.924)[27]$.

Instrumentation of the root canal and Er:YAG laser/ $2940 \mathrm{~nm} / 1.5 \mathrm{~W}$ irradiation

$(\log \mathrm{CFU} / \mathrm{ml}=2.113)[27]$.

Instrumentation of the root canal and Nd:YAG laser/ $1064 \mathrm{~nm} / 1.5 \mathrm{~W}$ irradiation

$(\log \mathrm{CFU} / \mathrm{ml}=2.477)$ [27].

Instrumentation of the root canal and Ho:YAG laser/ $2130 \mathrm{~nm} / 0.8 \mathrm{~W}$ irradiation

$(\log \mathrm{CFU} / \mathrm{ml}=2.491)$ [27].

Instrumentation of the root canal followed by irrigation with $1.25 \% \mathrm{NaOCl}(\log \mathrm{CFU} / \mathrm{ml}=2.522)$ [28].

Instrumentation of the root canal and Ho:YAG laser/ $2130 \mathrm{~nm} / 1.5 \mathrm{~W}$ irradiation

$(\log \mathrm{CFU} / \mathrm{ml}=2.531)$ [27].

Instrumentation of the root canal and Er:YAG laser/ $2940 \mathrm{~nm} / 0.001 \mathrm{~W}$ irradiation

$(\log \mathrm{CFU} / \mathrm{ml}=2.772)[28]$.

Instrumentation of the root canal followed by irrigation with $1 \% \mathrm{NaOCl}(\log \mathrm{CFU} / \mathrm{ml}=3.138)[25]$.

Instrumentation of the root canal and Nd: YAG laser/ $1064 \mathrm{~nm} / 0.8 \mathrm{~W}$ irradiation

$(\log \mathrm{CFU} / \mathrm{ml}=3.204)[27]$.

Instrumentation of the root canal and Er:YAG laser/ $2940 \mathrm{~nm} / 0.003 \mathrm{~W}$ irradiation

$(\log \mathrm{CFU} / \mathrm{ml}=3.251)[28]$.

Instrumentation of the root canal and diode laser/665 $\mathrm{nm} / 1 \mathrm{~W}$ irradiation combined with $\mathrm{MB}$ as photosensitizing agent and PBS (Phosphate-Buffered Saline) broth

$(\log \mathrm{CFU} / \mathrm{ml}=3.341)$ [34].

Instrumentation of the root canal and diode laser/665 $\mathrm{nm} / 1 \mathrm{~W}$ irradiation combined with $\mathrm{MB}$ as photosensitizing agent $(\log \mathrm{CFU} / \mathrm{ml}=3.344)[34]$.

Instrumentation of the root canal and Nd:YAG laser/ $1064 \mathrm{~nm} / 10 \mathrm{~Hz} / 15 \mathrm{sec}$ irradiation $(\log \mathrm{CFU} / \mathrm{ml}=3.374)$ 
[29].

Instrumentation of the root canal combined with $\mathrm{MB}$ as photosensitizing agent

$(\log \mathrm{CFU} / \mathrm{ml}=3.814)$ [34].

Instrumentation of the root canal combined with $\mathrm{MB}$ as photosensitizing agent and PBS (Phosphate-Buffered Saline) broth $(\log C F U / \mathrm{ml}=3.906)$ [34]

Instrumentation of the root canal and Nd:YAG laser/ $1064 \mathrm{~nm} / 5 \mathrm{~Hz} / 15 \mathrm{sec}$ irradiation $(\log \mathrm{CFU} / \mathrm{ml}=3.993)$ [29].

C) Analysis of the Mean Averages of Microbial Survival in General

The survival of 10 microorganisms well connected with endodontic problems: E. faecalis, S. anginosus, F. nucleatum, A. israelii, $P$. gingivalis, $P$. intermedia, A. naeslundii, $P$. aeruginosa, E. coli, and S. aureus was examined by 10 groups of researchers regarding the bactericidal effect of 30 different treatment protocols on them. In the first place the majority of them performed chemomechanical preparation and in the second place they contaminated the root canals with one or more microorganisms. Then, they completed the root canal preparation and either used or not laser irradiation with or without specific solutions. The $\log \mathrm{CFU} / \mathrm{ml}$ ranges from 0 to 7.940 (Table 23).

The best treatment protocols for root canal disinfection in descending order are as follows:

Instrumentation of the root canal followed by irrigation with $5.25 \% \mathrm{NaOCl}(\log \mathrm{CFU} / \mathrm{ml}=0)[29]$.

Instrumentation of the root canal and Er:YAG laser/ $2940 \mathrm{~nm} / 0.8 \mathrm{~W}$ irradiation

$(\log \mathrm{CFU} \mathrm{ml}=1.924)$ [27].

Instrumentation of the root canal and Er:YAG laser/ $2940 \mathrm{~nm} / 1.5 \mathrm{~W}$ irradiation

$(\log \mathrm{CFU} / \mathrm{ml}=2.133)$ [27].

Instrumentation of the root canal and diode laser/665 $\mathrm{nm} / 1 \mathrm{~W}$ irradiation with the combined effect of Methylene Blue (MB) as photosensitizing agent $(\log \mathrm{CFU} /$ $\mathrm{ml}=2.490)[33,34]$.

Instrumentation of the root canal and Ho:YAG laser/ $2130 \mathrm{~nm} / 0.8 \mathrm{~W}$ irradiation

$(\log C F U / m l=2.491)$ [27].

Instrumentation of the root canal followed by irrigation with $1.25 \% \mathrm{NaOCl}(\log \mathrm{CFU} / \mathrm{ml}=2.522)$ [28].

Instrumentation of the root canal and Ho: YAG laser/ $2130 \mathrm{~nm} / 1.5 \mathrm{~W}$ irradiation

$(\log \mathrm{CFU} / \mathrm{ml}=2.531)[27]$.

Instrumentation followed by irrigation with $2.5 \%$ $\mathrm{NaOCl}(\log \mathrm{CFU} / \mathrm{ml}=2.602)[31]$.

Instrumentation of the root canal and Er:YAG laser/ $2940 \mathrm{~nm} / 0.001 \mathrm{~W}$ irradiation

$(\log \mathrm{CFU} / \mathrm{ml}=2.772)[28]$.

Instrumentation of the root canal with the combined effect of Methylene Blue (MB) as photosensitizing agent $(\log \mathrm{CFU} / \mathrm{ml}=3.002)[33,34]$.

Instrumentation of the root canal and diode laser/665 $\mathrm{nm} / 1 \mathrm{~W}$ irradiation

$(\log \mathrm{CFU} / \mathrm{ml}=3.033)[33,34]$.

Instrumentation followed by irrigation with $1 \% \mathrm{NaOCl}$ $(\log \mathrm{CFU} / \mathrm{ml}=3.138)[25]$.

Instrumentation of the root canal and Nd:YAG laser/ $1064 \mathrm{~nm} 0$. W irradiation

$(\log \mathrm{CFU} / \mathrm{ml}=3.204)[27]$.

Instrumentation of the root canal and Er:YAG laser/ $2940 \mathrm{~nm} / 0.03 \mathrm{~W}$ irradiation

$(\log \mathrm{CFU} / \mathrm{ml}=3.251)[28]$.

Instrumentation of the root canal and Nd:YAG laser/ $1064 \mathrm{~nm} / 10 \mathrm{~Hz} / 15 \mathrm{sec}$ irradiation $(\log \mathrm{CFU} / \mathrm{ml}=3.374)$ [29].

Instrumentation of the root canal and Nd:YAG laser / $1064 \mathrm{~nm} / 5 \mathrm{~Hz} / 15 \mathrm{sec}$ irradiation $(\log \mathrm{CFU} / \mathrm{ml}=3.993)$ [29].

\section{DISCUSSION}

Generally, it is well known that certain microorganisms are related to specific pathological situations in endodontics. Being aware of them is necessary so as to be able to consider the importance of the disinfection capacity of each treatment plan. Consequently, it has been proved that:

1) With symptomatic endodontic disease and apical bone resorption T. denticola is associated [1].

2) In endodontically infected teeth without a sinus tract $E$. faecalis and Strept. anginosus were mostly found [2].

3) In teeth with necrotic pulp P. gingivalis, $P$. endodontalis, $P$. intermedia, and $P$. nigrescens were identified more frequently [4].

4) With root canal treatment failures E. faecalis is associated $[1,3]$.

5) In endodontically infected teeth with sinus tracts $P$. gingivalis and F. nucleatum were mostly identified [2].

This systematic review identified 10 in vitro studies that examined the effectiveness of treatment protocols, among classical methods and/or various laser applications in root canal disinfection. The results of these 10 studies indicated that the treatments which provide the best bactericidal ability regarding each bacterial solely and all of them were, in descending order of efficacy:

\subsection{Enterococcus faecalis}

Instrumentation of the root canal and diode laser/665 nm/ $1 \mathrm{~W}$ irradiation with the combined effect of Methylene Blue (MB) as photosensitizing agent seemed to be better in root canal disinfection than instrumentation of the root 
canal and diode laser/665 nm/1 W irradiation. In addition, the last method was slightly better than instrumenttation of the root canal combined with MB as photosensitizing agent and significantly better than instrumentation followed by irrigation with $2.5 \% \mathrm{NaOCl}$ (sodium hypochloride).

Regarding the instrumentation and diode laser/830 nm/ $3 \mathrm{~W}$ irradiation where no $\mathrm{CFU} / \mathrm{ml}$ was found, this is due to the lack of sensitivity of the methodology used to detect low concentrations of viable cells (contact with author).

\subsection{Streptococcus anginosus}

Instrumentation of the root canal and diode laser/635 $\mathrm{nm} / 0.1 \mathrm{~W}$ irradiation combined with RTF (reduced transferred fluid) and/or TBO (toluidine blue), as well as instrumentation with RTF and/or TBO demonstrated neither accepted nor satisfying reduction of $S$. anginosus $(\log \mathrm{CFU} / \mathrm{ml}=5.000, \log \mathrm{CFU} / \mathrm{ml}=6.079, \log \mathrm{CFU} / \mathrm{ml}=$ 6.113 and $\log \mathrm{CFU} / \mathrm{ml}=6.204$, respectively).

\subsection{Fusobacterium nucleatum}

Instrumentation of the root canal and diode laser/635 $\mathrm{nm} / 0.1 \mathrm{~W}$ irradiation combined with RTF (reduced transferred fluid) and/or TBO (toluidine blue), as well as instrumentation with RTF and/or TBO showed insufficient disinfection of F. nucleatum. ( $\log \mathrm{CFU} / \mathrm{ml}=4.176$, $\log$ $\mathrm{CFU} / \mathrm{ml}=6, \log \mathrm{CFU} / \mathrm{ml}=5.939$ and $\log \mathrm{CFU} / \mathrm{ml}=5.986$, respectively).

\subsection{Escherichia coli}

Instrumentation of the root canal followed by irrigation with $1.25 \% \mathrm{NaOCl}$ seemed to be better in root canal disinfection than instrumentation of the root canal and Er:YAG laser/2940 nm/0.001 W irradiation. Furthermore, instrumentation of the root canal followed by irrigation with $1 \% \mathrm{NaOCl}$ was less effective than the previous treatments, but slightly better than instrumentation of the root canal and Er:YAG laser/2940 nm/0.003 W irradiation.

\subsection{Actinomyces naeslundii}

Instrumentation of the root canal followed by irrigation with $5.25 \% \mathrm{NaOCl}$ seems to be the best in root canal disinfection as with this concentration no viable cells of Actinomyces naeslundii are detected. This method is used and mentioned only by one group of researchers [29].Concerning the other treatments, they are significantly worse and in fact instrumentation of the root canal and Nd:YAG laser/1064 nm/10 Hz/15 sec irradiation is slightly better than the same method but with $5 \mathrm{~Hz}$ irradiation or instrumentation solely.

\subsection{Staphylococcus aureus}

Instrumentation of the root canal followed by irrigation with $1.25 \% \mathrm{NaOCl}$ was better enough than instrumentation and Er:YAG laser/2940 nm/0.001 W irradiation and seemed to be better in root canal disinfection than instrumentation of the root canal followed by irrigation with $1 \% \mathrm{NaOCl}$ and instrumentation with Er:YAG laser/ $2940 \mathrm{~nm} / 0.003 \mathrm{~W}$ irradiation.

\subsection{Pseudomonas aeruginosa}

Instrumentation of the root canal followed by irrigation with $5.25 \% \mathrm{NaOCl}$ was the best in root canal disinfection, as no $\mathrm{CFU} / \mathrm{ml}$ of Pseudomonas aeruginosa was found. This method was conducted by one group of researchers [29]. Regarding instrumentation and Nd:YAG laser/1064 nm/10 Hz/15 sec irradiation, it was moderately worse than the previous one.

\subsection{Crobial Studies Results}

Instrumentation of the root canal followed by irrigation with $5.25 \% \mathrm{NaOCl}$ seemed to be the best in root canal disinfection as no viable cells were detected. However, this concentration of $\mathrm{NaOCl}$ is not used in vivo because it actively attacks living tissue without contributing significantly to treatment [35]. Furthermore, instrumentation and Er:YAG laser/2940 nm/0.8 W irradiation was well successful and slightly better than the same treatment but with 1.5 Watt irradiation, which was also better than instrumentation of the root canal and Nd:YAG laser/1064 nm/1.5 W irradiation. Also, instrumentation of the root canal and Ho: YAG laser/2130 nm/0.8 W irradiation was effective enough, as well as instrumentation of the root canal followed by irrigation with $1.25 \%$ $\mathrm{NaOCl}$ and instrumentation followed with Ho:YAG laser/2130 nm/1.5 W irradiation. Finally, instrumentation of the root canal and Er:YAG laser/2940 nm/0.001 W irradiation was less effective than the previous methods. All the other methods seemed to be worse in root canal disinfection.

\subsection{Microbial Survival in General}

Instrumentation of the root canal followed by irrigation with $5.25 \% \mathrm{NaOCl}$ seemed to be the best in root canal disinfection as no viable cells were detected. Instrumentation and Er:YAG laser/2940 nm/0.8 W irradiation was well successful and slightly better than the same treatment but with 1.5 Watt irradiation. Instrumentation followed with diode laser $/ 665 \mathrm{~nm} / 1 \mathrm{~W}$ irradiation with the combined effect of Methylene Blue (MB) as photosensitizing agent showed the same results when compared to instrumentation of the root canal and Ho:YAG laser/ $2130 \mathrm{~nm} / 0.8 \mathrm{~W}$ irradiation. Also good results show instrumentation of the root canal followed by irrigation with $1.25 \% \mathrm{NaOCl}$ and Ho:YAG laser/2130 nm/1.5 W irradiation which both are slightly better than instru- 
mentation followed by irrigation with $2.5 \% \mathrm{NaOCl}$ and Er:YAG laser/2940 nm/0.001 W irradiation. All the other methods seemed to be worse in root canal disinfection.

\section{CONCLUSIONS}

There are treatment protocols with the assistance or not of laser irradiation that can eliminate E. faecalis, E. coli and $S$. aureus inside the root canal. However, there is a serious number of $S$. anginosus, F. nucleatum, A. naeslundii and $P$. aeruginosa that remain inside the root canal even after laser irradiation. In vitro, $\mathrm{NaOCl} 5 \%$ seems to be the strongest solution in root canal disinfection. Concluding, it seems that new research is needed in order to set a treatment protocol effective in the root canal disinfection from all bacteria mentioned above that are related to endodontic origin pathology.

\section{REFERENCES}

[1] Foschi, F., Cavrini, F., Montebugnoli, L., Stashenko, P., Sambri, V. and Prati, C. (2005) Detection of bacteria in endodontic samples by polymerase chain reaction assays and association with defined clinical signs in Italian patients. Oral Microbiology and Immunology, 20, 289-295. doi:10.1111/j.1399-302X.2005.00227.x

[2] Sassone, L., Fidel, R., Faveri, M., Fidel, S., Fiqueiredo, L. and Feres, M. (2008) Microbiological evaluation of primary endodontic infections in teeth with and without sinus tract. International Endodontic Journal, 41, 508-515. doi:10.1111/j.1365-2591.2008.01397.x

[3] Gomes, B., Pinheiro, E., Gadê-Neto, C., Sousa, E., Ferraz, C., Zaia, A., et al. (2004) Microbiological examination of infected dental root canals. Oral Microbiology and Immunology, 19, 71-76. doi:10.1046/j.0902-0055.2003.00116.x

[4] Gomes, B., Jacinto, R., Pinheiro, E., Sousa, E., Zaia, A., Ferraz, C., et al. (2005) Porphyromonas gingivalis, Porphyromonas endodontalis, Prevotella intermedia and Prevotella nigrescens in endodontic lesions detected by culture and by PCR. Oral Microbiology and Immunology, 20, 211-215. doi:10.1111/j.1399-302X.2005.00214.x

[5] Sousa-Neto, M., Marchesan, M., Pécora, J., Junior, A., Silva-Sousa, Y. and Saquy, P. (2002) Effect of Er:YAG laser on adhesion of root canal sealers. Journal of Endodontics, 28, 185-187. doi:10.1097/00004770-200203000-00010

[6] Schoop, U., Kluger, W., Dervisbegovic, S., Goharkhay, K., Wernisch, J., Georgopoulos, A., et al. (2006) Innovative wavelengths in endodontic treatment. Lasers in Surgery and Medicine, 38, 624-630. doi:10.1002/1sm.20331

[7] Jha, D., Guerrero, A., Ngo, T., Helfer, A. and Hasselgren, G. (2006) Inability of laser and rotary instrumentation to eliminate root canal infection. Journal of the American Dental Association, 137, 67-70.

[8] Garcez, A., Ribeiro, M., Tegos, G., Núñez, S., Jorge, A. and Hamblin, M. (2007) Antimicrobial photodynamic therapy combined with conventional endodontic treat- ment to eliminate root canal biofilm infection. Lasers in Surgery and Medicine, 39, 59-66.

doi:10.1002/1sm.20415

[9] Blum, J., Michailesco, P. and Abadie, M. (1997) An evaluation of the bactericidal effect of the Nd:YAP laser. Journal of Endodontics, 23, 583-585. doi:10.1016/S0099-2399(06)81127-1

[10] Dostálová, T., Jelínková, H., Housová, D., Sulc, J., Nemeć, M., Dusková, J., et al. (2002) Endodontic treatment with application of Er:YAG laser waveguide radiation disinfection. Journal of Clinical Laser Medicine and Surgery, 20, 135-139. doi:10.1089/104454702760090218

[11] Fegan, S. and Steiman, H. (1995) Comparative evaluation of the antibacterial effects of intracanal Nd:YAG laser irradiation: An in vitro study. Journal of Endodontics, 21, 415-417. doi:10.1016/S0099-2399(06)80827-7

[12] Fonseca, M., Júnior, P., Pallota, R., Filho, H., Denardin, O., Rapoport, A., et al. (2008) Photodynamic therapy for root canals infected with Enterococcus faecalis. Photomedicine and Laser Surgery, 26, 209-213. doi:10.1089/pho.2007.2124

[13] Gordon, W., Atabakhsh, V., Meza, F., Doms, A., Nissan, R., Rizoiu, I., et al. (2007) The antimicrobial efficacy of the erbium, chromium:yttrium-scandium-gallium-garnet laser with radial emitting tips on root canal dentin walls infected with Enterococcus faecalis. Journal of the American Dental Association, 138, 992-1002.

[14] Gutknecht, N., Nuebler-Moritz, M., Burghardt, S. and Lampert, F. (1997) The efficiency of root canal disinfection using a holmium:yttrium-aluminum-garnet laser in vitro. Journal of Clinical Laser Medicine and Surgery, 15, $75-78$

[15] Hardee, M., Miserendino, L., Kos, W. and Walia, H. (1994) Evaluation of the antibacterial effects of intracanal Nd:YAG laser irradiation. Journal of Endodontics, 20, 377-380. doi:10.1016/S0099-2399(06)80294-3

[16] Kreisler, M., Kohnen, W., Beck, M., Al-Haj, H., Christoffers, A., Götz, H., et al. (2003) Efficacy of $\mathrm{NaOCl} / \mathrm{H}_{2} \mathrm{O}_{2}$ irrigation and GaAlAs laser in decontamination of root canals in vitro. Lasers in Surgery and Medicine, 32 189-196. doi:10.1002/1sm.10148

[17] Moritz, A., Gutknecht, N., Goharkhay, K., Schoop, U., Wernisch, J. and Sperr, W. (1997) In vitro irradiation of infected root canals with a diode laser: Results of microbiologic, infrared spectrometric, and stain penetration examinations. Quintessence International, 28, 205-209.

[18] Moshonov, J., Orstavik, D., Yamauchi, S., Pettiette, M. and Trope, M. (1995) Nd:YAG laser irradiation in root canal disinfection. Endodontics \& dental traumatology, 11, 220-224. doi:10.1111/j.1600-9657.1995.tb00492.x

[19] Perin, F., França, S., Silva-Sousa, Y., Alfredo, E., Saquy, P., Estrela, C., et al. (2004) Evaluation of the antimicrobial effect of Er:YAG laser irradiation versus 1\% sodium hypochlorite irrigation for root canal disinfection. Australian Endodontic Journal, 30, 20-22. doi:10.1111/j.1747-4477.2004.tb00162.x

[20] Ramsköld, L., Fong, C. and Strömberg, T. (1997) Thermal effects and antibacterial properties of energy levels required to sterilize stained root canals with an $\mathrm{Nd}$ :YAG laser. Journal of Endodontics, 23, 96-100. doi:10.1016/S0099-2399(97)80253-1

[21] Schoop, U., Goharkhay, K., Klimscha, J., Zagler, M., 
Wernisch, J., Georgopoulos, A., et al. (2007) The use of the erbium, chromium:yttrium-scandium-gallium-garnet laser in endodontic treatment: the results of an in vitro study. Journal of the American Dental Association, 138 , 949-955.

[22] Schoop, U., Moritz, A., Kluger, W., Patruta, S., Goharkhay, K., Sperr, W., et al. (2002) The Er:YAG laser in endodontics: results of an in vitro study. Lasers in Surgery and Medicine, 30, 360-364. doi:10.1002/1sm.10054

[23] Soukos, N., Chen, P., Morris, J., Ruggiero, K., Abernethy, A., Som, S., et al. (2006) Photodynamic therapy for endodontic disinfection. Journal of Endodontics, 32, 979984. doi:10.1016/j.joen.2006.04.007

[24] Vezzani, M., Pietro, R., Silva-Sousa, Y., Brugnera-Junior, A. and Sousa-Neto, M. (2006) Disinfection of root canals using Er:YAG laser at different frequencies. Photomedicine and Laser Surgery, 24, 499-502. doi:10.1089/pho.2006.24.499

[25] Folwaczny, M., Mehl, A., Jordan, C. and Hickel, R. (2002) Antibacterial effects of pulsed Nd:YAG laser radiation at different energy settings in root canals. Journal of Endodontics, 28, 24-29. doi:10.1097/00004770-200201000-00006

[26] Bergmans, L., Moisiadis, P., Teughels, W., Van Meerbeek, B., Quirynen, M. and Lambrechts, P. (2006) Bactericidal effect of $\mathrm{Nd}$ :YAG laser irradiation on some endodontic pathogens ex vivo. International Endodontic Journal, 39, 547-557. doi:10.1111/j.1365-2591.2006.01115.x

[27] Moritz, A., Schoop, U., Goharkhay, K., Jakolitsch, S., Kluger, W., Wernisch, J., et al. (1999) The bactericidal effect of Nd:YAG, Ho:YAG, and Er:YAG laser irradiation in the root canal: An in vitro comparison. Journal of Clinical Laser Medicine and Surgery, 17, 161-164.

[28] Mehl, A., Folwaczny, M., Haffner, C. and Hickel, R.
(1999) Bactericidal effects of $2.94 \mu \mathrm{m}$ Er:YAG-laser radiation in dental root canals. Journal of Endodontics, 25, 490-493. doi:10.1016/S0099-2399(99)80288-X

[29] Piccolomini, R., D'Arcangelo, C., D'Ercole, S., Catamo, G., Schiaffino, G. and De Fazio, P. (2002) Bacterologic evaluation of the effect of $\mathrm{Nd}$ :YAG laser irradiation in experimental infected root canals. Journal of Endodontics, 28, 276-278. doi:10.1097/00004770-200204000-00004

[30] Bergmans, L., Moisiadis, P., Huybrechts, B., Van Meerbeek, B. and Quirynen, M.P.L. (2008) Effect of photo-activated disinfection on endodontic pathogens ex vivo. International Endodontic Journal, 41, 227-239. doi:10.1111/j.1365-2591.2007.01344.X

[31] Wang, Q., Zhang, C. and Yin, X. (2007) Evaluation of the bactericidal effect of Er,Cr:YSGG, and Nd:YAG lasers in experimentally infected root canals. Journal of Endodontics, 33, 830-832. doi:10.1016/j.joen.2007.03.017

[32] De Souza, E., Cai, S., Simionato, M. and Lage-Marques, J. (2008) High-power diode laser in the disinfection in depth of the root canal dentin. Oral Surgery, Oral Medicine, Oral Pathology, Oral Radiology \& Endodontics, 106, 68-72. doi:10.1016/j.tripleo.2008.02.032

[33] Foschi, F., Fontana, C., Ruggiero, K., Riahi, R., Vera, A., Doukas, A., et al. (2007) Photodynamic inactivation of enterococcus faecalis in dental root canals in vitro. Lasers in Surgery and Medicine, 39, 782-787. doi:10.1002/1sm.20579

[34] Fimple, J., Fontana, C., Foschi, F., Ruggiero, K., Song, X., Pagonis, T., et al. (2008) Photodynamic treatment of endodontic polymicrobial infection in vitro. Journal of Endodontics, 34, 728-734. doi:10.1016/j.joen.2008.03.011 